\section{Mortality and alcohol consumption}

\section{Non-drinkers shouldn't be used as baseline}

EDITOR,-The interpretation of the finding that light or moderate drinkers have a lower mortality than non-drinkers remains controversial. ${ }^{\prime}$ The original cohort of 34000 male doctors was recruited in 1951, and information on alcohol consumption was obtained from the surviving third of the men some 27 years later (1978) and from the surviving quarter 40 years later (1991). The authors make no comment on the possible implications of these large gaps in time or on the issue of survivorship.

The British regional heart study has shown that middle aged male non-drinkers are likely to be exdrinkers, are older, and have higher rates of a wide range of diseases and of drug treatment than light or moderate drinkers. ${ }^{2}$ Non-drinkers should not be used as a baseline against which to measure the effects of alcohol consumption. The proportion of British doctors who are ex-drinkers cannot be assessed on the basis of those few non-drinkers who spontaneously mentioned previous drinking, and further estimates of previous drinking are based on survivors 40 years after recruitment, who are obviously likely to be healthier than those who died. There is a clear tendency between 1978 and 1990 for men drinking $\geqslant 15$ units a week to move towards lighter or non-drinking status rather than continuing with a stable intake (table II in the paper), and Wannamethee and I have shown that diminishing alcohol intake with increasing age is closely associated with increasing ill health and drug treatment. ${ }^{3}$

Non-drinking doctors have a higher mortality than drinkers even when divided into those with and without "previous disease." Because the shape of the two curves is similar Richard Doll and colleagues conclude that previous disease has little relevance to the relation observed between alcohol intake and mortality, although they have not adequately examined the characteristics of nondrinkers in either group.

In the study of British doctors deaths from ischaemic heart disease showed no significant trend with alcohol intake, although non-drinkers had a somewhat higher mortality than those drinking 1-14 drinks a week. An early report from the British regional heart study also showed no significant relation between alcohol intake and the incidence of heart attacks, although men drinking 1-2 British units daily had the lowest incidence. ${ }^{4}$ This group contained the lowest proportion of current smokers and had the lowest mean blood pressure and body mass index and the highest levels of physical activity in leisure time. Doll and colleagues have not examined the issue of such advantageous characteristics, although they might be more relevant than the direct effects of alcohol. In a 9.5 year follow up of the cohort in the British regional heart study men drinking 2-6 British units a day showed a non-significant reduction in the risk of death from ischaemic heart disease compared with occasional drinkers, little reduction in total cardiovascular mortality, and no reduction in total mortality. ${ }^{5}$

Doll and colleagues' conclusion that the present guidelines should acknowledge the important disadvantages to health of total abstinence goes beyond the information available in their study. It implies that middle-aged and elderly British men should drink alcohol to reduce their risk of death from all causes. Surely it would be preferable to attempt to reduce the population risk of premature death by paying attention to smoking, diet, and physical activity? Emeritus professor of clinical epidemiology

\section{Royal Free Hospital School of Medicine,}

London NW/3 2 PF

1 Doll R, Peto R, Hall E, Wheatley K, Gray R. Mortality in relation to consumption of alcohol: 13 years' observations on male British doctors. BMf 1994;309:911-8. (8 October.)

2 Wannamethee G, Shaper AG. Men who do not drink: a repot fon from the

3 Wannamethee G, Shaper AG. Changes in drinking habits in middle-aged British men. $f R$ Coll Gen Pract 1988;38:440-2.

4 Shaper AG, Phillips AN, Pocock SJ, Walker M. Alcohol and ischaemic heart disease in British middle-aged men. BM 1987;294:733-7.

5 Shaper AG, Wannamethee G, Walker M. Alcohol and coronar heart disease. A perspective from the British regional hear study. Int f Epidemiol 1994;23:482-94.

\section{The dose-response relation is probably} linear

EDrToR,-Richard Doll and colleagues claim a U shaped dose-response curve for mortality and alcohol. 'If valid, their observations have profound implications for health education. Their findings are being widely interpreted as proving that drinking a few drinks every day leads to a longer life than drinking no alcohol at all. Regrettably, the infelicitous design of their questionnaire means that the reported findings are invalid and the conclusions potentially seriously misleading. The questionnaire was faulty in at least three ways: it
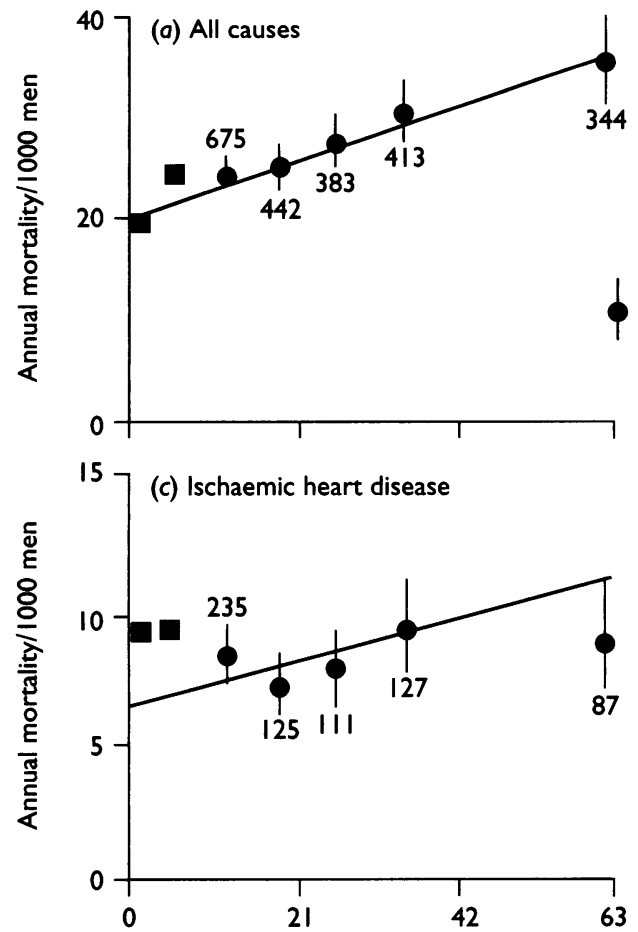

failed to differentiate subjects who had never been drinkers from former drinkers; it failed to differentiate former drinkers who had successfully abstained from those who had relapsed but who happened not to be drinking at that time; and it invited those who preferred not to state their consumption to say that they were drinking less often than weekly, thus inviting respondents to conceal the extent of their consumption.

The authors' post hoc attempt to separate never drinkers from former drinkers must have greatly underestimated the number of former drinkers. Surveys suggest that the true number of former drinkers was likely to have been about $33 \%$ of self reported non-drinkers and not $3 \%$ as claimed. ${ }^{2}$ To this number must be added an unknown number of drinkers who stated that they were non-drinkers (say, $10 \%$ ). Thus $43 \%$ of non-drinkers could have been former drinkers or heavy drinkers. Additionally there would have been an unknown number of heavy drinkers claiming to be light drinkers (again, say, 10\%).

Evidence of misclassification is provided by the data for disease augmented by alcohol. Among 19 deaths in non-drinkers eight were due to cancers of the upper aerodigestive tract or liver and two were due to cirrhosis of the liver. This provides evidence that up to 10 of the $19(53 \%)$ non-drinkers were or had been heavy drinkers.

Probably $43-53 \%$ of doctors classified as nondrinkers therefore were or had been heavy drinkers. I have assumed here that the true figure was $50 \%$ and have corrected for misclassification using the assumption that the mortality for nondisclosing and former drinkers was high, corresponding to a consumption of 84 units a week. The corrected results are consistent with a linear doseresponse relation (figure) suggesting that alcoho

(b) Alcohol augmented causes

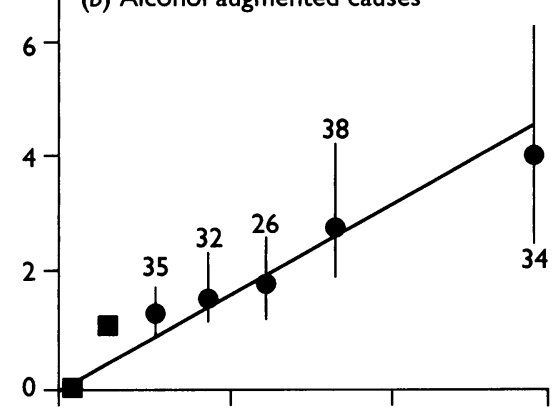

307 (d) Other causes

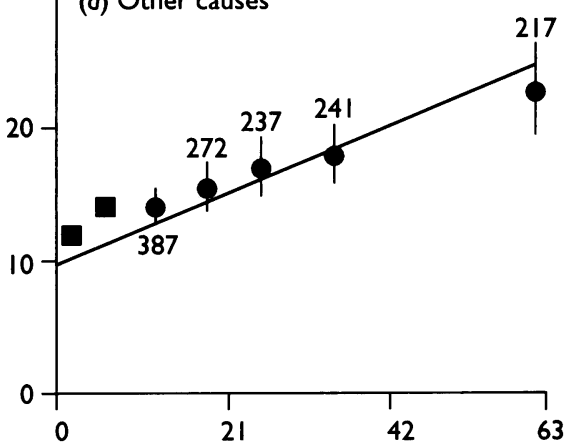

Weekly alcohol consumption (British units)

Annual mortality per 1000 men from (a) all causes, (b) alcohol augmented causes, (c) ischaemic heart disease, and (d) other known causes by alcohol consumption when data from Doll and colleagues' study are corrected for misclassification at zero and light drinking (1-7 units) points 
consumption carries no benefit in terms of mortality. Pending further studies, it would be prudent from a health promotion perspective not to advocate alcohol consumption as a procedure for extending life but to assume that the dose-response relation for mortality and alcohol consumption is linear with a positive slope.

Health Research Centre,

School of Psychology,

Middlesex University,

Enfield,

Middlesex EN3 4SF

1 Doll R, Peto R, Hall E, Wheatley K, Gray R. Mortality in relation to consumption of alcohol: 13 years' observations on relation to consumption of alcohol: 13 years' observations
male British doctors. $B M$ f $^{\prime}$ 1994;309:911-8. (8 October.)

2 Cox BD, Blaxter M, Buckle ALJ, Fenner NP, Golding JF, Gore $\mathrm{M}$, et al. The health and lifestyle survey. London: Health Promotion Trust, 1987

\section{Moderate drinking also improves health}

EDrTOR,-Richard Doll and colleagues convincingly show the beneficial effect of mild to moderate alcohol consumption on the risk of death from ischaemic heart disease and from several other causes. ${ }^{1}$ No published report seems to exist, however, on the effect of sensible alcohol consumption on health status. We describe the relation between alcohol use and quality of life related to health, based on the findings of a survey that we undertook in West Glamorgan in 1993.

The method and main findings of the study, including the aging effect of smoking, have been fully described elsewhere. ${ }^{23}$ In essence, a random sample of adults ( $n=827$, response rate $82 \%$ ) were interviewed in their own home by trained health visitors who used a structured questionnaire. This contained the short form 36 and a variety of questions on smoking habits, alcohol intake, and history of chronic illness. On alcohol consumption, participants were asked to indicate whether they drank alcohol and, specifically, whether they had consumed any alcohol in the past week. Subjects who answered "yes" were further prompted to quantify their consumption. Four categories of drinkers were derived: non-drinkers; mild drinkers ( $\leqslant 14$ units a week for women and $\leqslant 21$ units a week for men); moderate drinkers (15-34 units a week and 21-49 units a week respectively); and severe drinkers ( $>34$ units a week and $>49$ units a week respectively).

Of the 827 participants, 337 were non-drinkers, 403 mild drinkers, 66 moderate drinkers, and 21 severe drinkers. Mean scores obtained with the short form 36 in the four categories were determined for each of the eight parameter scores, and the differences between drinkers and non-drinkers were compared. Multiple regression was used to adjust for age, sex, social class, smoking habits, and the presence of chronic illness.

Our results showed that the mild to moderate drinkers reported a significantly better health

Mean difference in SF-36 scores between mild drinkers and non-drinkers and between moderate drinkers and nondrinkers (adjusted for age, sex, social class, smoking habits, and presence of chronic illness)

\begin{tabular}{lcc}
\hline & $\begin{array}{c}\text { Mild } \\
\text { drinkers } v \\
\text { non-drinkers }\end{array}$ & $\begin{array}{c}\text { Moderate } \\
\text { drinkers } v \\
\text { non-drinkers }\end{array}$ \\
\hline Physical functioning & $4 \cdot 7^{\star \star}$ & $8 \cdot 7^{\star \star \star}$ \\
Role limitations due to & $6 \cdot 4^{\star \star}$ & $10 \cdot 0^{\star \star}$ \\
physical problems & $4 \cdot 9^{\star \star}$ & $2 \cdot 5$ \\
Bodily pain & $3 \cdot 7^{\star \star}$ & $1 \cdot 5$ \\
General health perception & $3 \cdot 3^{\star}$ & $2 \cdot 9$ \\
Vitality & $6 \cdot 9^{\star \star \star}$ & 0.7 \\
Social functioning & $2 \cdot 2$ & $5 \cdot 2$ \\
Role limitations due to & $1 \cdot 1$ & 0.1 \\
emotional problems & $2 \cdot 1$ \\
Mental health & & \\
\hline
\end{tabular}

$\star \mathrm{P}<0 \cdot 1, \star \star \mathrm{P}<0.05, \star \star \star \mathrm{P}<0.01$. experience than did the non-drinkers: they perceived themselves to be more physically active and to experience fewer role limitations due to physica problems (table). In addition, the mild drinkers experienced significantly less bodily pain and perceived themselves to be more healthy, to have more vitality, and to be generally more sociable than did the non-drinkers. We have not presented the results for the severe drinkers because the sample was too small to yield any reliable estimate.

Thus mild to moderate alcohol consumption seems to confer not only longevity but also a better quality of life related to health. The biblical advice by the apostle Paul to Timothy urging him to stop drinking only water and start using a little wine $e^{4}$ is thus scientifically sound and valid. The implication for prevention is not to pursue a population strategy aimed at lowering the average alcohol consumption as this is likely to produce less health gain (and may even produce health loss) but to target preventive efforts at high risk drinkingthat is, pursue the high risk strategy. ${ }^{5}$

RONAN A LYONS

Consultant

SU VUI LO

Senior registrar

STEPHEN MONAGHAN Senior registra

BEVERLEY N C LITTLEPAGE

Department of Public Health Medicine,

Directo

West Glamorgan Health Authority,

Swansea SA1 $5 \mathrm{AQ}$

1 Doll R, Peto R, Hall E, Wheatley K, Gray R. Mortality in relation to consumption of alcohol: 13 years' observation on male British doctors. BMF 1994;309:911-8. (8 October.)

2 Lyons RA, Lo SV, Littlepage BNC. Perception of health amongst ever-smokers and never-smokers: a comparison using the SF-36 health status questionnaire. Tobacco Control 1994;3: 213-5.

3 Lyons RA, Lo SV, Littlepage BNC. Comparative health status of patients with 11 common illnesses in Wales. I Epidemiol Community Health 1994;48:388-90.

4 Holy Bible. 1 Timothy v, 23. (New International Version.)

5 Rose G. The strategy of preventive medicine. Oxford: Oxford University press, 1992

\section{The conclusions we draw}

EDITOR,-Richard Doll and colleagues' finding that all cause mortality in men is lowest among those who drink 21 units of alcohol a week can be interpreted differently depending on the observer's stance. ${ }^{1}$

The teetotaller-It's so unfair!

The average drinker-The doctors were wrong the safe limit isn't 21 , it's 63 . So back to life as normal: drink what you like-in moderation.

The heavy drinker-Drinking four and half pints of beer a night has about the same risk as no drinking at all. I like a few pints and don't mind a little extra risk, so I'll stick to six pints (or seven etc).

The insurance company-We must add an extra question to proposals for life insurance asking whether prospective customers drink 21 units of alcohol a week and if not why not. If they don't we'll weight their premiums.

The health fanatic-This is a better excuse than "rehydrating myself" for drinking one and a half pints of beer every night after a game of squash.

The standpoint of the authors seems to be that of the health fanatic, with length of life rather than quality and enjoyment being the prime objective. Most doctors whom I know would prefer the second viewpoint - that of the average drinkerand would drink within reason while accepting risk no greater than that of teetotallers. Overall, the main conclusion that many people will draw from the study is that drinking alcohol is not as bad as some people say. ${ }^{23}$
1 Doll R, Peto R, Hall E, Wheatley K, Gray R. Mortality in relation to consumption of alcohol: 13 years' observations on male British doctors. $B M$ F $^{7}$ 1994;309:911-8. (8 October)

2 Department of Health. Action against alcohol misuse. London HMSO, 1991.

3 Secretary of State for Health. The health of the nation. London: HMSO, 1992.

\section{Length of femoral neck and rates of hip fractures}

\section{Measurements may not be reliable}

EDITOR,- - Too little attention has been given to the relation between anatomical structure and risk of fracture. Ian R Reid and colleagues report the relation between the length of the femoral neck and rates of hip fracture, ${ }^{1}$ but they in fact measured the projected length of the femoral neck. This varies with the degree to which the femur is rotated around its shaft axis. In neutral position the neck usually points somewhat anteriorly and is thus shortened on the frontal projection. As the femur is rotated inward its projected length increases. Frontal radiographs of the hip are usually obtained with the femur rotated inward, but practice varies, and it cannot be assumed that identical projections were obtained in independent routine radiographs obtained with an interval of 40 years. The authors must therefore show that, on average, the projections of the femoral neck were identical in 1950 and 1990.

For correct measurement of the length the long axis of the femoral neck must be parallel to the film. For this, however, anteversion of the femoral neck must be corrected for. Because of the great variability of this, with a range of nearly $30^{\circ}$ in most populations, correct positioning is impossible without three dimensional radiography. A computer program is now available for measuring the length of the femoral neck on dual $x$ ray absorptiometry of the hip. This measurement is made with the foot rotated inward, but no individual differentiation is made for the degree of anteversion of the femoral neck. Therefore this measurement may not give a reliable individual assessment of the length of the femoral neck.

\section{ARNE HøISETH} Radiologist

Sentrum Røntgeninstitutt,

Oslo,

Norway

1 Reid IR, Chin K, Evans MC, Jones JG. Relation between increase in length of hip axis in older women between 1950 and 1990s and increase in age specific rates of hip fracture. $B M F$ 1994;309:508-9. (20-27 August.)

\section{Author's reply}

EDITOR,-I agree that the length of the hip axis measured from radiographs depends on femoral rotation and that this cannot be directly assessed from the plain radiographs used in our study. We were aware of this potential problem and excluded films that showed incorrect positioning or in which there was appreciable disease of the hip joint, which might have compromised hip positioning. During both periods pelvic radiographs were routinely obtained with the legs internally rotated. As Arne Høiseth points out, it is impossible to be sure that positioning was the same at two periods so widely separated in time, but there is no reason to believe that any change in radiographic technique occurred. Indeed, inspection of the two sets of films suggests that the degree of internal rotation was not different between the groups. 